\title{
Patrimônio cultural rural paulista: diálogos entre o turismo e a educação não formal
}

\section{Rural cultural heritage in São Paulo state: dialogues between tourism and non-formal education}

\author{
Livia Morais Garcia Lima1 \\ liviamglima@gmail.com
}

\section{Resumo}

Este artigo tem por objetivo refletir sobre a contribuição do turismo e da educação não formal nos estudos sobre o patrimônio cultural rural no estado de São Paulo. Foi utilizada uma metodologia de caráter qualitativo, com ênfase na metodologia da história oral, em associação com registros em diário de campo e a produção de registros fotográficos dos trabalhos de campo realizados. Conclui-se a importância da discussão do turismo no campo da educação não formal e que o uso do patrimônio vem adquirindo novos sentidos e funcionalidades. $\mathrm{O}$ turismo pode ser, sem dúvidas, uma ferramenta educacional, através de um processo que é, ao mesmo tempo, enriquecedor e prazeroso para o turista, o que o aproxima do campo da educação não formal.

Palavras-Chave: Patrimônio; Turismo; Fazendas Históricas.

\begin{abstract}
This article aims to reflect on the contribution of tourism and non-formal education in studies of the rural cultural heritage in the state of São Paulo. It was used a qualitative methodology with emphasis on oral history methodology, in combination with daily records of field and the production of photographic records of the fieldwork. The conclusion is that the tourism discussion is very important for the non-formal education field and that the use of the heritage has been acquiring new meanings and functionalities. Tourism can be, no doubt, an educational tool, through a process that is, at the same time, enriching and enjoyable for the tourist, who approaches to the non-formal education field.
\end{abstract}

Keywords: Heritage; Tourism; Historical Farms.

1 Bacharel em Turismo pela Universidade Estadual Paulista (Unesp), mestre em Gerontologia pela Universidade Estadual de Campinas, e doutora em Educação pela Faculdade de Educação da mesma universidade (FE/Unicamp). 


\title{
Introdução
}

Este artigo tem por objetivo refletir sobre a contribuição do turismo e da educação não formal nos estudos sobre o patrimônio cultural rural no estado de São Paulo. Na pesquisa, o patrimônio foi explorado como espaço turístico educacional, dentro de uma visão de educação não formal no contexto rural, através de um turismo cultural em espaço rural que explique e contextualize a relação urbano/rural para os adultos e velhos que visitam as fazendas.

\begin{abstract}
Tem-se observado que a cidade, independente de sua localização ou de seu tamanho, constrói-se pela acumulação de imagens múltiplas e variadas, reais e imaginadas, que atraem e criam o desejo de experimentar o seu charme, de penetrar e de descobrir os seus mistérios. Este poder de atração da cidade predispõe ao turismo (ALMEIDA, 2010, p. 11).
\end{abstract}

Optei por assumir o termo velho ou idoso pelo fato destas categorias delimitarem com maior clareza as representações pelas as quais a velhice vem passando, enquanto o tratamento como terceira idade, melhor idade, idade de ouro, idade legal, dentre outras, são aqui consideradas subterfúgios semânticos, isto é, palavras aprazíveis que têm, no entanto, o propósito de encobrir um debate mais importante, que é a função social da velhice na nossa sociedade, em que o velho é alvo do mercado consumidor crescente, como por exemplo, o mercado turístico.
O uso da designação "terceira idade" ou "melhor idade" ao invés de velhice vêm provo- car um novo sentido que seria o sentido da não velhice, negando o sentido histórico da velhice como declínio, incapacidade, fragilidade e como fase de resignação às perdas da beleza e da capacidade físico-cognitiva. Essa nova sensibilidade considera a juventude como um valor dissociado à categoria etária, que deve ser preservado na vida das pes- soas envelhecidas (OLIVEIRA, 2009, p. 37).

Também sobre a concepção de velhice ativa atrelada à ideia de terceira idade, Debert (1999) enfatiza o quanto essa expressão e os movimentos que se organizam em torno dela indicam mudanças radicais na forma como o envelhecimento é visto, deixando de ser compreendido como decadência física, perda de papéis sociais e retraimento. A autora cita como exemplo o grande número de programas para a "terceira idade" no Brasil, como os grupos de convivência, as escolas abertas e as universidades. Dessa forma, justifico a utilização do termo idoso ou velho no presente artigo.

O espaço empírico da pesquisa foi o das fazendas históricas paulistas, selecionadas pelo projeto em Políticas Públicas em andamento, denominado Patrimônio Cultural Rural Paulista: espaço privilegiado para pesquisa, educação e turismo, contemplado na Oitava Chamada para o Programa de Pesquisa em Políticas Públicas (PPPP). O projeto foi financiado pela Fundação de Amparo à Pesquisa do Estado de São Paulo (Fapesp), em parceria com o Centro de Memória - Unicamp (CMU), no período de 2008 a 2012, ao qual a pesquisa esteve vinculada.

O projeto PPPP/FAPESP reuniu dezoito propriedades em regiões significativas do Estado de São Paulo, sendo essas definidas pelos núcleos regionais compostos pelas cidades de Campinas, Limeira-Rio Claro, São Carlos-Araraquara, Itu, Mococa- Casa Branca e Vale do Paraíba. Teve como objetivo principal disponibilizar um conjunto de instrumentos e de metodologias de gestão, de conservação e de difusão para os responsáveis por esse patrimônio cultural rural, tanto os proprietários quanto as respectivas instâncias públicas pertinentes à área da cultura, da educação e do turismo. Vale lembrar ainda a Associação das Faz̧endas Históricas Paulistas, OSCIP (Organização da Sociedade Civil de Interesse Público) responsável por reunir essas propriedades históricas dos séculos XVIII, XIX, e início do século XX que trabalham com turismo no espaço rural.

Segundo Tognon (2007), coordenador do projeto, o Patrimônio Cultural Rural pode ser definido como o conjunto de registros materiais e imateriais decorrentes das práticas, dos costumes e das iniciativas produtivas que se estabelecem, historicamente e territorialmente, na área rural.

As propriedades pesquisadas surgiram em decorrência da ocupação da região central paulista nos séculos XVIII e XIX, dada a grande diversidade de bens que formam o seu patrimônio histórico cultural e natural. Essa diversidade de bens culturais se, por um lado, representa uma grande potencialidade para as atividades de pes- 
quisa e para as ações de políticas públicas, por outro, apresenta permanentemente desafios no estabelecimento de procedimentos metodológicos que permitem a descoberta, a identificação, a caracterização, a análise e a descrição desses bens. Marins completa a ideia da importância dos estudos do meio rural paulista, afirmando:

\begin{abstract}
Se hoje compreendermos as manifestações da arquitetura rural antes como suportes de memórias sociais e como documentos históricos sobre a vida social e material das populações brasileiras - e não apenas como monumentos que celebram uma visão cristalizada e excludente da sociedade brasileira baseada no cânone nacional -, a proteção de edificações e agenciamentos espaciais constitui imenso desafio às políticas de preservação do patrimônio cultural, especialmente no caso paulista (MARINS, 2013, p. 164).
\end{abstract}

Dessa perspectiva, o autor ainda nos chama a atenção para que o atual território paulista abriga exemplares significativos de testemunhos arquitetônicos das culturas do trigo quinhentista e seiscentista, da produção de açúcar difundida durante a segunda metade do século XVIII, das fazendas de criações, da gigantesca vaga cafeicultora, das culturas de abastecimento e de ocorrências mais pontuais, como o algodão e a produção leiteira, muitas vezes ampliada e adaptada no tempo por culturas que se sucederam.

Tognon (2007) ainda ressalta que tal Patrimônio Cultural Rural possui um perfil múltiplo, em escalas e tipologias que contemplam não só as fazendas históricas e os complexos produtivos antigos, mas também usinas e barragens para a implementação das pioneiras redes de produção e distribuição de energia elétrica do campo e da cidade, pontes, diques, ferrovias, enfim, registros edificados no território agrário que se somam aos acervos artísticos, bibliotecas, arquivos, equipamentos e máquinas, festas e arte popular, hábitos, costumes, crenças e modos de fazer.

Tognon (2003, p. 163) complementa a ideia ao caracterizar "os bens culturais como sendo os mais importantes resultados históricos da cultura humana na constituição do seu território", tanto que estariam ganhando cada dia mais espaço nas políticas públicas, estendendo-se aos poucos pelo Brasil através da associação a programas de estímulos a polos turísticos.

Dessa perspectiva, o patrimônio imaterial ou intangível, segundo Pelegrini e Funari (2008), dá alma aos espaços concretos monumentais, sendo transmitido de geração a geração. É conceituado a partir da perspectiva da alteridade, sendo considerado alvo de constantes recriações decorrentes das mutações entre as comunidades e os grupos que convivem num dado espaço social, do meio ambiente, das interações com a natureza e da própria história dessas populações. Em outras palavras, o patrimônio imaterial é o "saber fazer" e o "saber viver", e não o seu produto.

Existem muitas definições de patrimônio imaterial ou intangível, mas a que mais se adequa ao tipo de pesquisa que realizo é aquela que o salienta enquanto fruto da vida em sociedade. Assim, para que ele exista e possa ser apreendido, é necessária a presença de uma comunidade com intensa vida social, capaz de gerar manifestações culturais como ritos, festas, quermesses, novenas, crenças, e romarias, e que produzam músicas, danças, poesias, rezas e, criações nas artes plásticas, no artesanato e no folclore local.

Os usos, as representações, as expressões, os conhecimentos e os modos de fazer compartilhados pelas comunidades são entendidos como aspectos do seu patrimônio cultural imaterial. Assim, ele é recriado constantemente por uma comunidade, através dos seus saberes e fazeres, que são transmitidos de geração em geração, principalmente pela oralidade, e permitem que seus integrantes construam um sentimento de identidade.

Das dezoito fazendas históricas envolvidas na presente pesquisa, três foram selecionadas levando-se em conta o desenvolvimento de atividades de turismo cultural e educação patrimonial nas mesmas e sua localização em espaços centrais do estado de São Paulo: Fazenda Quilombo, localizada no município de Limeira; Fazenda Santo Antônio da Água Limpa, localizada no município de Mococa; e Fazenda Bela Vista, localizada no município de Dourado.

A escolha dessa área central do estado justifica-se pela concentração de fazendas históricas disponíveis e sensíveis à proposta, além de ser uma região que foi constituída, segundo o relatório de pesquisa do Projeto Fazendas ${ }^{2}$, por meio de fazendas de café, de relações econômicas e sociais que deram origem a mui-

2 Projeto aprovado no Programa Auxílio à Pesquisa - Regular - Chamada 09/2011 de Propostas Fapesp SEC/Condephaat: inventários de identificação, análise e seleção do Patrimônio Cultural Paulista, desmembrado em dois processos. 
Dossiê

tas das práticas culturais paulistas, tornando-se, portanto, representativa da integração da cultura caipira aos novos modos de vida trazidos pelo migrante (nacional ou internacional).

Em relação aos estudos no meio rural o neologismo rurbanização ${ }^{3}$ será empregado neste artigo, pois tenho consciência do caráter difuso das fronteiras desses espaços.

Mas a crise do mundo rural e as perspectivas em que a mesma tem vindo a ser discutida, revelam que o espaço rural é portador de novas dinâmicas que convidam a novas abordagens e obrigam a redefinir os termos do debate sobre o mundo rural (PEIXOTO, 2004. p. 2).

Nesse sentido, o mundo rural é hoje atravessado por uma nova valorização, decorrente das procuras alternativas de lazer, longe das grandes metrópoles, do turismo de massas", "sendo definido como um cenário da educação não formal, marcado pela descontinuidade, pela eventualidade, pela informalidade" (ANTUNES, 2007, p. 29).

\title{
Educação não formal e turismo: diálogos possíveis
}

Trilla (2011) afirma que a educação é uma realidade complexa, dispersa, heterogênea e versátil, o que nos faz concluir que a educação envolve algo muito mais amplo do que pensar somente o espaço escolar.

La educación, desde el punto de vista de sus efectos, es un proceso holístico y sinérgico, un proceso cuya resultante no es la simple acumulación o suma de las distintas experiencias educativas que vive el sujeto, sino una combinación mucho más compleja en la que tales experiencias se influyen mutuamente (TRILLA, 2011, p. 188).

Deixo claro que, no presente artigo, não minimizo o papel da escola, concordando com Fernandes:

Em qualquer ambiente educativo, seja formal/escolar, não formal/não escolar ou informal/incidental, qualquer ponto serve como partida para uma tessitura de conhecimentos, experiências, vivências, aprendizagens que se projetam no tempo e no espaço e que se desenvolvem formando redes, teias, em que um ponto puxa e se liga, se conecta a outro (FERNANDES, 2007, p. 28).

Dessa perspectiva, Trilla (2011) afirma que a escola é seguramente a instituição pedagógica mais importante que uma sociedade pode ter, mas, segundo o autor, apesar de sua indiscutível relevância, a escola é apenas um dos ambientes em que ocorre a educação e não está apta para qualquer tipo de objetivo educativo.

\begin{abstract}
Assumimos como pressuposto orientador que a educação, na sua amplitude e complexidade, só é significativa quando ocorre em contextos significativos de ação, não sendo, por isso, apenas redutível aos espaços e tempos da instituição escolar [...]. Na ausência de estudos ou de indicadores precisos que contribuam para a caracterização do vasto campo educativo na sua amplitude sociológica, não custa admitir, porém, que se vem assistindo ao crescimento e a expansão de processos, contextos e formas de educação não escolares, tanto nas vertentes não formais como nas vertentes informais (PALHARES, 2008, p. 109).
\end{abstract}

3 O neologismo rurbano ou rurbanização foi empregado por Gilberto Freyre (1982), para definir uma comunidade que habita um perímetro conceitualmente definido como urbano, mas que, na realidade, continua mantendo suas características rurais. São cidades com menos de 10 mil habitantes, conforme o grau de densidade de ocupação humana nesse perímetro, urbano ou não urbano. Assim, como afirma o autor, o conceito de rurbanização é um processo de desenvolvimento socioeconômico que combina, como formas e conteúdos de uma só vivência regional - a do Nordeste, por exemplo, ou a do Brasil como um todo - valores e estilos de vida rurais e valores e estilos de vida urbanos.

4 Considerando-se o volume, o turismo pode ser de minorias ou de massas. Este critério não se refere ao número de pessoas que viajam em determinada ocasião, mas ao número de pessoas que habitualmente demanda certo tipo de serviço. Aquelas destinações que todo mundo quer, pertencem ao turismo de massas. (BARRETO, 2003, p. 18). 
A esse respeito, Palhares (2013) afirma que a escola é uma instituição que exerce uma força radicalizadora na separação das educações e no quadro da ideologia da aprendizagem ao longo da vida. Segundo o autor, a instituição caminha agora para um maior enclausuramento disciplinar, cujo cenário de crise econômica e financeira ajudou a operar.

As escolas estão obcecadas na procura de soluções para melhoria dos resultados escolares,
um (suposto) requisito, sine qua non, para sua própria sobrevivência. Os resultados dos
exames adquiriram uma importância na seriação das escolas, no seu financiamento, na
manutenção dos postos de trabalho dos docentes e funcionários, entre outras funções no
quadro das atuais políticas educativas, que, por vezes, se ignora o seu papel pedagógico e
o seu impacto na construção de percursos escolares dos alunos (PALHARES, 2013, p. 2).

No estado atual do nosso país, a maioria dos indivíduos já frequentou a escola, seja por um período pequeno de tempo, completando o ensino médio ou mesmo o ensino superior. Assim, todos nós temos histórias sobre essa experiência e o que ela significa ou significou, e como consequência, o que a educação é ou deveria ser. Mesmo aqueles que não tiveram a chance de frequentar a escola, ouviram histórias daqueles que o fizeram e guardam um desejo forte de fazê-lo, como demonstram a pesquisa de Souza (2011) e os estudos realizados com alunos dos cursos de alfabetização de jovens e adultos ${ }^{5}$.

Assim, ao longo desse escrito, ressalto o quão presente a educação formal se encontra em nossa sociedade, uniformizando os padrões sociais. O espaço da escola é marcado pela formalidade, regularidade e sequencialidade. São por esses motivos que, no presente artigo, discuto a importância de variados processos e mecanismos educativos, entre eles os espaços não escolares e as áreas de atuação da educação não formal.

Pensar a educação, nas suas diversas vertentes, equivale, deste modo, a pensar a sociedade, porquanto uma coisa e outra são efetivamente indissociáveis. A educação não se esgota, portanto, em considerações pedagógicas que a coloquem num nível de justificação teórica meta-social. O fim de compreender a educação através de uma conceitualização honesta passa, portanto, necessariamente por uma análise sociológica da mesma (FREITAS, 2012, p. 104-105).

Esta análise sociológica ao qual o autor se refere parte da premissa de que não é possível compreender os objetivos da educação sem analisar respectivamente os sujeitos ativos e passivos da educação, isto é, a partir de uma perspectiva sociológica, os atores que intervêm nos processos educativos. Nesse sentido, Fernandes afirma:

O termo educação envolve um leque amplo de experiências educativas, informativas e formativas que não se resume à experiência escolar, formal. Embora a escola seja uma instituição com muitos anos de existência, participando ativamente dos repertórios culturais de diferentes contextos e deixando marcas indeléveis - positivas e/ou negativas - nas memórias de seus freqüentadores, desde há muito tempo também aparecem experiências formativas ocorrendo fora das escolas para diferentes públicos (FERNANDES, 2007, p. 5-6).

A autora ressalta que crianças, jovens, adultos e velhos de qualquer classe social e econômica precisam ter direito e acesso a muitas formas de aprendizagem, sociabilidade e socialização que não apenas as oferecidas pelos sistemas formais de ensino, legalizados e submetidos a padronizações sistemáticas.

É essa discussão realizada por Freitas (2012) que vem de encontro a presente pesquisa, quando pensamos a educação enquanto um fenômeno especificamente humano e ancorado em um processo de transmissão cultural ao longo de toda a vida do indivíduo, seu desenvolvimento e sua integração à sociedade.

A educação entendida na perspectiva do desenvolvimento humano ao longo de todo o ciclo de vida poderá constituir a mais valia para o desenvolvimento de uma sociedade

5 Grupo de Estudo e Pesquisa em Educação de Jovens e Adultos (Gepeja), da Universidade Estadual de Campinas, certificado pelo CNPq. Professores responsáveis: Dra. Sonia Giubilei e Dra. Débora Cristina Jeffrey. 
Dossiê

pluralista e democrática onde todos, independentemente da idade, possam viver e conviver (RODRIGUES, 2009, p. 273).

Segundo Blunt (1988), as especificidades da educação são muitas, entre elas a educação não formal, que vem ocupando um espaço que merece atenção, tanto no cenário nacional quanto no internacional. Para Trilla (2011, p.11), a "educação não formal se refere a todas aquelas instituições, atividades, meios, âmbitos de educação que, não sendo escolares, são criadas especificamente para satisfazer determinados objetivos educativos". É preciso destacar que, para o autor, a educação não formal não possui um método específico e realiza-se através de procedimentos, opondo-se aos que são próprios da escolarização convencional. Complementando essa ideia, Almerindo Janela Afonso ressalta:
A educação não formal, embora obedeça também a uma estrutura e a uma organização (distintas, porém das escolas) e possa levar a uma certificação (mesmo que não seja essa a finalidade) diverge ainda da educação formal; no que respeita à não fixação de tempos e locais e à flexibilidade na adaptação dos conteúdos de aprendizagem a cada grupo concreto (AFONSO, 1989, p. 78).

Outro autor português, Marcelino de Sousa Lopes, também realiza discussões sobre a educação não formal e, afirma que:

\begin{abstract}
Podemos considerá-la como uma educação não regulada por normas rígidas. É norteada pelos propósitos do pluralismo educativo e centrados na relação interpessoal. Apresenta ainda as seguintes características: tendência educativa assente no pluralismo e na partilha vivencial; propósito de complemento em relação à educação formal, ênfase na convivência geradora de afetos, nivelamento tendencialmente horizontal das relações humanas, aproximando as pessoas umas das outras sem as valorizar em funções de grau acadêmico; não outorgar títulos acadêmicos, mas certificados e diplomas de participação; abrangência a toda a população, promovendo relações e aprendizagens intergeracionais; recursos a metodologias próprias com recusa à reprodução de procedimentos utilizados pelo sistema educativo institucional (LOPES, 2006, p. 404).
\end{abstract}

Em relação à bibliografia brasileira sobre o conceito, Simson, Park e Fernandes afirmam:
A educação não formal, por poder lidar com outra lógica espaço-temporal, por não necessitar se submeter a um currículo definido a priori, por dar espaço para receber temas, assuntos, variedades que interessam ou sejam válidos para um público específico naquele determinado momento e que esteja participando de propostas, programas ou projetos nesse campo, faz com que cada trabalho e experimentação sejam únicos. E, por envolver profissionais e freqüentadores que podem exercitar e experimentar outro papel social, que não o representado na escola formal (como professores e alunos), contribui com uma maneira de lidar com o cotidiano, com os saberes, com a natureza e com a coletividade (SIMSON, PARK \& FERNANDES, 2007, p. 13).

Já Valéria Aroeira Garcia (2009), autora da primeira tese brasileira sobre o surgimento e o papel da educação não formal, afirma:
A educação não formal pode considerar, valorizar e reafirmar a cultura dos indivíduos nela envolvidos, incluindo educadores e educandos, fazendo com que a bagagem cultu- ral que cada um traz seja respeitada e esteja presente no decorrer de todos os trabalhos, procurando não somente respeitar e valorizar a realidade de cada um, mas indo além, fazendo com que essa realidade perpasse todas as relações (GARCIA, 2009, p. 53).

6 Tradução livre da autora. 
Em relação à bibliografia brasileira, autores como Garcia (2009) afirmam que, até bem pouco tempo, essa modalidade educacional quase não era considerada como um campo específico dentro do contexto educacional no Brasil e, em sua tese de doutoramento, analisa o campo da educação não formal a partir das políticas públicas para crianças e adolescentes, contexto em que é considerada sua relação com a educação social.

Nessa direção, podemos pensar as fazendas históricas selecionadas pela presente pesquisa como instituições não específicas de educação não formal. Assim, temos que diferenciar entre as várias fazendas. Há aquelas que já incluem nas atividades oferecidas aos turistas, atividades educativas, como aulas de gastronomia, com degustação dos pratos locais, outras que promovem sessões de contação de causos, e ainda aquelas em que tais atividades acontecem de maneira natural, seguindo a programação da visita ou visitas guiadas que têm uma nítida função de educar pelo exemplo concreto de traços do passado, encontráveis ainda na realidade da propriedade.

De acordo com Trigo (1996, p. 11), “o turismo faz parte de um universo maior denominado lazer", entendido como "todas as atividades desenvolvidas fora do sistema produtivo (trabalho), das obrigações sociais, religiosas e familiares".

Barretto (2003) complementa o conceito afirmando que a complexidade e a diversidade inerentes ao tema originaram uma enorme quantidade de definições, que variam conforme a formação do autor e que, atualmente, conta com pelo menos cem diferentes tipos de turismo. Nesse sentido, a concepção economicista que comumente se faz dele, entende o turismo como um setor de atividades "com saldos e contas arrumados" (FREITAS, 2012, p. 232).

O conceito de turismo é, sem dúvida, para muitas áreas do conhecimento, algo polêmico. Grande parte do material escrito sobre turismo começa e não raro termina com a afirmação de que se trata de uma indústria, porque movimenta dinheiro, gera emprego e renda, o que é inegável, porém isso diz muito pouco (DA HORA; CAVALCANTI, 2003, p. 209).

Deixo claro nesse artigo que o turismo é visto pelas Ciências Sociais, como uma prática e manifestação social. Apesar de também ser usado e usar de estratégia para agregar valor e transformar o patrimônio em produto vendável, "o turismo inclui, de um lado, o planejamento e, do outro, a comercialização. Estes, em determinado momento passam a interagir, mas devem ser separados do ponto de vista conceitual" (BARRETTO, 2003, p. 12). A autora ainda afirma que a visão do turismo como comércio ou indústria tem sido predominante fora do meio acadêmico, o que causa a escassez de estudos sobre esse fenômeno social.

\footnotetext{
A prática do turismo parece ser, para a academia, um objeto de pouca relevância, porque os atores estariam praticando uma atividade alienada; enquanto isso, os turistas continuam tendo uma oferta alienante justamente por falta de pesquisa científica capaz de transformar esse suposto "ser genérico" denominado "o turista" em sujeitos concretos particularizados (BARRETTO, 2007, p. 14).
}

Assim, entendo o turismo como uma característica do homem contemporâneo. Como afirma Freitas (2012), todos nós somos turistas.

Ser turista é, portanto, um ideal: um ideal cosmopolita, um ideal humanista, um ideal aristocrático (regressemos ao sentido grego do termo, da Aretê), em suma, um ideal educativo. A única coisa de que podemos culpar-nos é de não sermos suficientemente turistas (FREITAS, 2012, p. 232).

Nessa perspectiva, o autor nos chama a atenção para que uma das características humanas mais ancestrais é a curiosidade. Esta curiosidade criou um habitual estímulo do homem à movimentação, do qual o turismo é uma das formas mais modernas de manifestação social, mantendo-se fiel à raiz etimológica do termo: a de uma viagem circular, de uma volta motivada pelo desejo de ver as coisas. 
Dossiê

Turismo deriva do grego tornos por via latina, transformado em tornare e referindo-se a um torno ou um círculo, com a denotação de um movimento circular executado em torno de um eixo. Os sufixos -ismo e -ista indicam, respetivamente, ação, processo, comportamento ou qualidade típica e aquele que executa essa ação (FREITAS, 2012, p. 73).

O antropólogo Santana (2009, p. 14) complementa a discussão afirmando que nem a guerra, nem a fome, nem a ânsia de reprodução foram capazes de mover a humanidade quanto à atividade turística, podendo atribuir a ela essa rede de expectativas, de desejos, de fantasias e estereótipos, "que fizessem do outro uma parte do paraíso particular, quase um para cada turista e para cada um dos que desejariam ser turistas".

O desejo de ver as coisas também suscita a necessidade de verificação empírica, surgindo dessa maneira a viagem, "a efetiva deslocação com o objetivo de ver, com os próprios olhos, como é o mundo fora do âmbito de referência imediato de um determinado indivíduo ou sociedade” (FREITAS, 2012, p. 73).

Dessa perspectiva, Urry (1996) analisa precisamente o olhar enquanto motivador e gerador de toda a práxis turística. $\mathrm{O}$ autor parte do pressuposto de que os turistas viajam para olhar para coisas, sendo assim consolidada a experiência turística.

Segundo Trigo (1996), o turismo surge a partir de meados do século XIX, na Europa e Reino Unido, como consequência do desenvolvimento tecnológico iniciado pela Revolução Industrial e da formação de parte da burguesia comercial e industrial com tempo, dinheiro e disponibilidade para viajar.

Não devemos nos esquecer de que as críticas mais recorrentes ao turismo baseiam-se inevitavelmente na superficialidade, sendo relativamente recente no Brasil a consciência sobre o fenômeno turístico como dimensão sociocultural e como um campo da ação humana.

Defendo uma posição contrária ao "economicismo", no que se refere ao caráter do Turismo como especialidade. Concordo que o Turismo é uma especialidade, mas não no sentido "tecnicista" muitas vezes defendido pelas "forças do mercado". O Turismo trata-se de uma série de ciências, ou melhor, de saberes aplicados para pensar, planejar e realizar as viagens do ser humano que deseja e precisa deslocar-se em busca de um grau ainda maior de plenitude humana (GROPPO, 2005, p. 36).

De acordo com Pérez (2009), o turismo é uma atividade complexa e mutável, que não deve ser reduzida exclusivamente a negócio, atividade industrial, marketing ou gestão de produtos, afirmando que o turismo é um fenômeno sociocultural que pode ser abordado com diferentes perspectivas disciplinares.

Desde a década de 1970, o turismo tem sido objeto de estudo sistematizado em múltiplas áreas do conhecimento para sua melhor compreensão, sendo a pesquisa científica sobre o tema explicitamente defendida por diversos autores.

O turismo como estudo vem ganhando adeptos em número cada vez maior e esta afirmação é facilmente verificável quando se comprova que a cada dia cresce mais o interesse pelo conhecimento do fato e do fenômeno "turismo" (ANSARAH, 1998, p. 2).

Barretto (2003) defendeu a urgência e importância de se realizar pesquisas em turismo que pudessem ajudar no planejamento do setor. Smith (1995) identificou seis ângulos do turismo a partir dos quais se realiza uma investigação turística: o turismo como experiência humana, o turismo como um comportamento social, o turismo como um recurso, o turismo como negócio, o turismo como uma indústria e, por fim, o turismo como debate intelectual.

Marins (2013) realiza a discussão que vai de encontro ao objeto de estudo da presente pesquisa, e afirma que o processo de abertura de fazendas históricas ao turismo no estado de São Paulo ainda não apresentou uma experiência regional de conservação de fazendas semelhante em escala à fluminense. $\mathrm{O}$ autor ressalta que esse processo obteve não apenas sucesso financeiro como uma repercussão na imprensa nacional, veiculando matérias que destacam o sucesso de público e a associação dos espaços preservados com o passado das elites imperiais. 
A conversão de fazendas paulistas de café em meios de hospedagem data, entretanto, já das últimas décadas do século XX, com experiências pioneiras de "hotéis-fazenda" em Campinas e Bananal. Essas iniciativas ganharam impulso, sobretudo, na primeira década do século XXI, quando várias outras fazendas aderiram à hospedagem ou ainda às práticas de acolhimento, semelhantes ao que também existe no Rio de Janeiro (MARINS, 2013, p. 175).

O autor ressalta que parte das propriedades abertas ao público passou então a constituir a referida Associação Fazendas Históricas Paulistas, "formalizada em março de 2007 e que coliga 14 fazendas localizadas primordialmente no Oeste paulista" (MARINS, 2013, p. 175).

E por acreditar que os três fenômenos que se cruzam nesta pesquisa - turismo, educação e patrimônio - são fenômenos sociais por excelência, optei também por utilizar a metodologia qualitativa no presente estudo.

\section{A História Oral como metodologia de pesquisa no estudo da intersecção entre educação, turismo e patrimônio}

Beni (1998, p. 21) afirma que, apesar de o turismo ser tema comum na grande imprensa, como um dos setores mais emergentes da economia mundial contemporânea, suas bases teóricas e metodológicas ainda estão em processo de construção.

A questão do método em turismo segue a dinâmica das ciências nas quais o turismo é
objeto de estudo. Muitas são as disciplinas que tratam da questão do turismo e temos
que admitir que ainda hoje o turismo não se constitui em um corpo de conhecimento
independente, com dinâmica própria (DENCKER, 1998, p. 27).

Nesse sentido, o autor afirma que o turismo não é uma disciplina e sim um objeto de estudo pertencente a várias disciplinas, de modo, que seu campo de estudo acaba por incorporar os métodos e técnicas das disciplinas, cujos olhares com ele se cruzam.

Ballantyne, Parker e Axelsen (2009) nos chamam a atenção para o fato da investigação em turismo não estar acompanhado as tendências da investigação em ciências sociais no que diz respeito aos recursos das metodologias qualitativas, sugerindo que é necessário desafiar os métodos estabelecidos e mais tradicionais, especialmente tendo em conta que a pesquisa em turismo tem muitos tópicos que se encontram em fases iniciais. Por isso, são comuns estudos do tipo exploratório e abertos à diversidade e à criatividade metodológica.

No sentido de "acreditar que a história oral é e sempre será uma prática de fronteiras, fronteiras entre disciplinas e possibilidades de uso" (WORCMAN, 2013, p. 149), é que a presente pesquisa utiliza uma metodologia de caráter qualitativo com ênfase no método biográfico, em associação com registros em diário de campo e a produção de registros fotográficos dos trabalhos de campo realizados.

As metodologias qualitativas, por romperem com as formas tradicionais de pesquisa, aproximaram os pesquisadores das pessoas, dos sujeitos, isto é, dos participantes da situação de aprendizagem. Nesse processo, como analisa Maria Isaura Pereira de Queiroz, ocorreu a valorização do singular, dos relatos pessoais, das testemunhas confiáveis (DEMARTINI, 2006, p. 101).

Em relação aos depoentes da pesquisa, houve a priorização dos visitantes adultos e idosos na fase de coleta de dados, porque no projeto percebo que o que buscamos é o prazer de conhecer os patrimônios materiais e imateriais, em um processo de autoconhecimento dos sujeitos observados que só acontece depois da idade adulta. Por isso, crianças e adolescentes que visitam as fazendas históricas, levados por uma exigência do currículo formal, não se coadunavam com o objetivo principal da pesquisa.

A metodologia da história oral vem contribuindo para a construção do corpus da pesquisa, porque 
Dossiê

vem tratando a entrevista com os participantes como um momento de troca entre o pesquisador e o pesquisado, permitindo assim novas reflexões sobre o imaginário e o espaço rural paulista.

A história oral, como metodologia de pesquisa e de investigação, busca conhecer o passado recorrendo à memória (lembranças e esquecimentos) e à fala do narrador, nunca buscando uma única versão dos fatos. Nesse sentido, Lang afirma:

\begin{abstract}
A história oral não é apenas uma técnica para coletar informações, mas uma metodologia de pesquisa que produz uma fonte especial, um meio para a produção de novos conhecimentos. Entende-se "metodologia" como o conhecimento crítico do processo de pesquisa; é um instrumento a serviço da pesquisa que visa determinados objetivos (LANG, 2010, p. 73).'
\end{abstract}

A autora ainda coloca que a história oral permite apreender sentimentos e emoções não revelados pelos documentos escritos, com base na palavra gravada de contemporâneos que relatam fatos, experiências e opiniões. Santhiago e Magalhães (2013) ainda ressaltam a metodologia como recurso valioso para variados estudos sobre vidas, sobre grupos sociais, sobre o presente.

No caso desta pesquisa, o depoimento oral é utilizado tanto em entrevistas com os proprietários das fazendas selecionadas, quanto com turistas. Nas visitas técnicas que realizei às propriedades históricas selecionadas, fiz uma rápida passagem pelo patrimônio arquitetônico preservado e escolhi um local mais calmo e isolado, solicitando então ao proprietário ali se situar para colher seu depoimento oral sobre a fazenda, com o objetivo de saber o que fazem e como fazem para repassar a história da propriedade e como entendem a importância de preservar o passado. Além disso, indagamos sobre o tipo de experiências que os visitantes esperam ter durante a visita e como o papel dos negros e dos imigrantes aparece na história da fazenda que é contada para os visitantes.

Também me preocupou saber se existem iniciativas, por parte do proprietário ou do poder público municipal, visando à divulgação do patrimônio intangível produzido localmente, para grupos de adultos e idosos que visitam a propriedade histórica, no intuito de rever aspectos do passado que foram importantes para familiares, amigos ou vizinhos de mais idade.

Em relação aos visitantes/turistas, algumas entrevistas foram realizadas em momentos posteriores ao momento de lazer, como foi o caso dos entrevistados que visitaram a Fazenda Quilombo, em que a visita era apenas uma visita - dia. Nesse caso, as entrevistas ocorreram na residência dos próprios depoentes. Já no caso da Fazenda Santo Antônio da Água Limpa e Fazenda Bela Vista, em que realizei o trabalho de campo por alguns dias seguidos nas propriedades, a proximidade entre pesquisador/pesquisado se intensificou e as entrevistas ocorreram de modo natural durante a estadia dos turistas na fazenda. Nesse sentido, Lang afirma:

\begin{abstract}
A entrevista é um diálogo entre o pesquisador e o entrevistado, e diálogo significa o encontro de duas intencionalidades. O pesquisador organiza a pesquisa para o conhecimento de um dado aspecto da realidade, escolhe os entrevistados e fará uso das informações obtidas. O entrevistado em sua fala recorre à memória e reconstrói o passado com os valores do presente e com as experiências vivenciadas. Sua narrativa pode conter esquecimentos e omissões deliberadas ou não. O entrevistado tem uma imagem de si e opiniões que quer transmitir (LANG, 2010, p. 74).
\end{abstract}

Dessa forma, o objetivo das entrevistas foi entender o motivo pelo qual visitantes/turistas resolveram visitar uma fazenda histórica, os interesses específicos e as experiências mais significativas vividas na propriedade. Além disso, busquei entender como os aspectos do patrimônio intangível se fazem presentes nas ações de turismo cultural e de educação patrimonial promovidas pelas fazendas históricas pesquisadas. No caso da Fazenda Santo Antônio da Água Limpa, procuramos saber o que os turistas acharam sobre ficar hospedado junto com a família dos proprietários na casa sede.

Nessa perspectiva, a metodologia da história oral vem nos possibilitando, a partir de diversas versões do passado, não só preencher lacunas sobre a história de cada tipo de fazenda selecionada pela pesquisa, mas principalmente perceber as relações sociais dos depoentes construídas ao longo das visitas realizadas às propriedades, visando a melhoria da compreensão da realidade rural paulista. 


\section{Considerações finais}

Frente aos dados expressos nas falas dos depoentes que participaram das entrevistas realizadas, observo que os visitantes dia ou excursionistas e os turistas que se hospedam nas propriedades, têm buscado tais atividades no sentido de vivenciarem concretamente experiências que os remetam a histórias e memórias difundidas no âmbito familiar, referentes a avós ou bisavós que emigraram para o Brasil para trabalhar como colonos em fazendas cafeeiras.

Estas propriedades apresentavam grande produção e obtinham muito lucro no final do século XIX e primeiras décadas do XX, exigindo para isso constante ampliação da mão de obra envolvida na produção cafeeira. Esse imaginário circulante no âmago das familias originárias da população migrante encontra uma espécie de concretização nas visitas a tais propriedades, que se voltam para as atividades turísticas e por isso recebem adultos e idosos que buscam entender, no concreto, suas histórias familiares, para poder repassá-las com segurança às novas gerações.

Gastronomia, modo de vida rural, memória e história das propriedades rurais são fatores aglutinadores que constituem um instrumento de ativação do imaginário individual e coletivo dos turistas que visitam as fazendas selecionadas pela pesquisa.

Dessa forma, esta pesquisa tem a intenção de contribuir para as discussões do campo da educação não formal, do patrimônio e do turismo cultural, dirigidas para o atendimento de adultos e velhos, pois é no ato de realizar uma visita a uma fazenda histórica que acontece o encontro, a socialização de vivências, dos interesses e das necessidades muitas vezes comuns, assim como o reforço de vínculos afetivos e o sentimento de pertencimento relacionado às suas histórias familiares ou a vínculos de amizade surgidos da própria história do turista em relação à fazenda visitada.

Com relação aos idosos participantes da presente pesquisa, foi constatada a existência de pessoas que demonstram satisfação com a sua vida adulta ou idosa, boa dose de autoestima e estado de ânimo elevado. Os proprietários das fazendas não os transformam em turistas com necessidades especiais, mas sim consideram a fragilidade própria de parte desse público, pensando em novas formas de integrá-los às atividades do local visitado.

Nesse sentido, as perspectivas da educação não formal ajudam a evidenciar o quão importantes e válidas se tornam as atividades turísticas para esse público, pois são atividades propícias à aprendizagem dessas pessoas que realizam as visitas. Isso nos permite, afirmar que a educação patrimonial não formal pode ser vista, então, como mais uma possibilidade de vivência educativa e pode atuar em outros setores, como o turismo cultural, sendo portanto flexível e respeitando as diferenças e capacidades de cada visitante, que experimentam e significam suas próprias vivências, acionando passados e futuros e demarcando rupturas.

Ressaltamos também, a importância da discussão do turismo cultural no campo da educação não formal e o uso do patrimônio, adquirindo novos sentidos e funcionalidades. O turismo cultural pode ser, sem dúvidas, uma ferramenta educacional, através de um processo que é, ao mesmo tempo, enriquecedor e prazeroso para o turista, o que o aproxima, do campo da educação não formal.

Turismo, educação e os usos do patrimônio material e imaterial são fenômenos sociais por excelência. Acredito, desta forma, que este artigo venha contribuir para uma reflexão no campo da educação não formal não como alternativa à escolarização, mas como parte integrante da discussão do tempo livre e do lazer como um campo da educação não formal que continua existindo ao longo da vida do indivíduo.

O patrimônio pode ser valorizado e promovido através da educação não formal, ajustado às condições e diversidades especificas de cada fazenda selecionada pela pesquisa em questão, tornando possível que o turista adquira um conhecimento da propriedade visitada, compreendendo e respeitando os patrimônios ali expressos e compartilhando os novos conhecimentos adquiridos com outras pessoas, tanto no momento da visita, como posteriormente.

\section{Referências}

AFONSO, Almerindo Janela. Sociologia da educação não formal: reactualizar um objecto ou construir uma nova problemática? In: ESTEVES, A. J.; STOER, S. R. A sociologia na escola. Porto: Afrontamento, 1989. 
Dossiê

ALMEIDA, Marina. Prefácio. In: PAES, Maria Teresa Duarte; OLIVEIRA, Melissa. (Orgs.). Geografia, Turismo e Patrimônio Cultural. São Paulo: Annablume, 2010.

ANSARAH, Marilia. Formação e capacitação do profissional em turismo e hotelaria. Reflexões e cadastro das instituições educacionais do Brasil. São Paulo: Aleph, 1998.

ANTUNES, Maria Costa. Educação Formal e Não Formal no Contexto da Educação ao Longo da Vida. Revista Educareducere, Portugal, v. 13, n. 20, jun. 2007.

BALLANTYNE, Richard; PACKER, James; AXELSEN, Mary. Trends in tourism research. Annals of Tourism Research, v. 36, n. 1, p. 149-152, 2009.

BARRETTO, Margarita. Manual de iniciação ao estudo do turismo. Campinas: Papirus, 2003.

Turismo e Identidade local: uma visão antropológica. Campinas: Papirus, 2001.

BENI, Mário. Análise Estrutural do Turismo. São Paulo: Senac, 1998.

BLUNT, Arnold. Education, Learning and development: envolving concepts. Convergence, v. 21, n. 1, p. 37-54, 1988.

CAMPOS, Teresinha. Lažer e Terceira Idade: contributos do Turismo no âmbito do Programa Clube da Melhor Idade. 2003. Dissertação (Mestrado em Educação) - Universidade Estadual de Campinas, Campinas. 2003.

DA HORA, Aline; CAVALCANTI, Karina. Turismo Pedagógico: Conversão e Reconversão do Olhar. In: REJOWSKI, Mirian; COSTA, Beatriz (Orgs.). Turismo Contemporâneo: Desenvolvimento, estratégia e gestão. São Paulo: Atlas, 2003.

DAVIS, Kate. Biography as critical methodology. Newsletter Research Committee of IS A, Utrecht University, n. 38, 2003.

DEBERT, Guita. Pressupostos da reflexão antropológica sobre a velhice. Textos didáticos, Campinas, n. 13, p. 7-30, jun. 1999.

DEMARTINI, Zeila. Memória e Educação. In: WORCMAN, K.; PEREIRA, J. V. História falada: memória, rede e mudança social. São Paulo: Sesc SP: Museu da Pessoa: Imprensa Oficial do Estado de São Paulo, 2006.

DENCKER, Aroldo. Metodologia científica. In: TRIGO, Luis (Org.). Turismo: como aprender, como ensinar. São Paulo: Senac, 1998.

FAUSTINO, Ricardo. O turismo em espaço rural como modo de valorização do Patrimônio Cultural: estudos de caso na média depressão periférica paulista: o caso das Fazendas Capoava e Ibicaba. 2006. Tese (Doutorado em Geografia) - Universidade de São Paulo, São Paulo. 2006.

FERNANDES, Renata Sieiro. A cidade educativa como espaço de educação não formal, as crianças e os jovens como indicadores ambientais. Paisagens em debate, São Paulo, v. 2, n. 5, p. 24-45, dez. 2007.

FREITAS, Jorge. Turismo Cultural e Educação de Adultos: Encontros e Desencontros. 2012. Dissertação (Mestrado em Educação) - Universidade do Minho, Portugal. 2012.

GARCIA, Valéria Aroeira. A educação não formal como acontecimento. 2009. Tese (Doutorado em Educação) - Universidade Estadual de Campinas, Campinas. 2009.

GROPPO, Luís Antônio. Turismo e Humanização. In: GROPPO, Luís Antônio; Candioto, Mario (Orgs.). Turismo: viajar, incluir e humanizar. Taubaté: Cabral Editora, 2005.

LANG, Ana Beatriz Gordo. História Oral: procedimentos e possibilidades. São Paulo: Ceru, 2010.

LOPES, Marcelino Souza. Animação Sociocultural em Portugal. Chaves, Portugal: Intervenção, 2006.

MARINS, Paulo. Preservação do patrimônio rural no Estado de São Paulo: entre ação governamental e práticas sociais. In: CORREIA, T. B.; BORTOLUCCI, M. A. P. C. S. (Orgs.). Lugares de produção: arquitetura, paisagens e patrimônio. São Paulo: Annablume, 2013.

MERCADANTE, Eduardo. Velhice: uma questão complexa. In: CÔRTE, B.; MERCADANTE, E. F.; ARCURI, I. 
Dossiê

G. (Orgs.). Velhice e Envelhecimento/ Complex(idade). São Paulo: Vetor, 2005.

OLIVEIRA, Glaucia Destro. Gestão e vivências de velbices nas Repúblicas de Idosos de Santos. 2009. Dissertação (Mestrado em Antropologia) - Universidade de São Paulo, São Paulo. 2009.

PALHARES, José Augusto. Gavetos, gavetas e en GAVEtados: Constrangimentos e dilemas dos jovens (enquanto alunos) na escola e para além dela. Portugal: Plataforma Barômetro Social, 2013.

Os sítios de educação e socialização juvenis: experiências e representações num contexto não-escolar. Revista Educação, Sociedade e Culturas, n. 27, p. 109-130, 2008.

PARK. Margarete. Educação formal versus educação não-formal: impasses, equívocos e possibilidades de superação. In: PARK, Margareth Brandini; FERNANDES, Renata Sieiro (Orgs.). Educação não-formal: contextos, percursos e sujeitos. Campinas: Unicamp/CMU; Holambra: Editora Setembro, 2005. p. 67-90.

PEIXOTO, Paulo. O desaparecimento do mundo rural. In: CONGRESSO LUSO-AFRO-BRASILEIRO DE CIÊNCIAS SOCIAIS: A questão social do novo milênio, 8, 2004, Coimbra. Anais... Portugal: Universidade de Coimbra, 2004.

PELEGRINI, Sandra; FUNARI, Pedro Paulo. O que é patrimônio cultural imaterial. São Paulo: Brasiliense, 2008.

PÉREZ, Xerardo. Turismo Cultural. Uma visão Antropológica. Colección Pasos Edita, Tenerife, Espanha, n. 2, 2009.

QUEIROZ, Maria Isaura Pereira. Relatos orais: do “indizivel” ao “dizível”. In: SIMSON, O. R. M. (Org.). Experimentos com Histórias de Vida (Itália - Brasil). São Paulo: Vértice, 1988.

RODRIGUES, Maria José. Cultura e lazer na terceira idade: proposta de intervenção. In: PEREIRA, J. D, L; LOPES, M. S. (Orgs.). Animação Sociocultural na Terceira Idade. Chaves, Portugal: Intervenção, 2009.

SANTANA, Augustín. Antropologia do Turismo: analogias, encontros e relações. São Paulo: Aleph, 2009.

SANTHIAGO, Ricardo; MAGALHÃES, Valéria Barbosa (Orgs.). Depois da utopia: a história oral em seu tempo. São Paulo: Letra e Voz: Fapesp, 2013.

SIMSON, Olga Rodrigues de Moraes. História Oral, memórias compartilhadas e empoderamento: um balanço de experiências de pesquisa. In: CONFERÊNCIA INTERNACIONAL DE HISTÓRIA ORAL, 14, 2006, Sidney. Anais... Sidney, Austrália: IOHA, 2006.

SIMSON, Olga Rodrigues de Moraes; GIGLIO, Zeila. A arte de recriar o passado: história oral e velhice bem-sucedida. In: NERI, A. N. (Org.). Desenvolvimento e Envelhecimento: Perspectivas Biológicas, Psicológicas, Sociológicas. Campinas: Papirus, 2001. (Coleção Vivaidade).

SIMSON, Olga Rodrigues de Moraes; PARK, Margarete; FERNANDES, Renata Sieiro (Orgs.). Educação não-formal: cenários da criação. Campinas: CMU/Unicamp, 2007.

SMITH, Mark. Issues in cultural tourism studies. Oxon: Routledge, 2015.

SOUZA, Carlos Pereira. As vožes dos educandos do projeto educativo de integração social - PEIS. 2011. Dissertação (Mestrado em Educação) - Universidade Estadual de Campinas, Campinas. 2011.

TOGNON, Marcos. Patrimônio Cultural Rural Paulista: espaço para pesquisa, educação e turismo. In: OITAVA CHAMADA PARA O PROGRAMA DE PESQUISAS EM POLÍTICAS PÚBLICAS DA FAPESP. Campinas: CMU/ Unicamp, 2007.

TOGNON, Marcos. Patrimônio: entre o passado e o presente. In: PARK, Margareth Brandini (Org.). Formação de educadores: memórias, patrimônio e meio ambiente. Campinas: Mercado de Letras, 2003.

TRIGO, Luis Godoy. Filosofia da formação profisssional nas sociedades pós-industriais. Um olhar para além do tradicional. O caso do lazer e do turismo. 2006. Tese (Doutorado em Educação) - Universidade Estadual de Campinas, Campinas. 1996. 
Dossiê

TRILLA, Jaume. Otras educaciones: animación sociocultural, formación de adultos y cuidad educativa. Barcelona: Editorial Anthropos, 1993.

. La educación fuera de la escuela. Ámbitos no formales y educación social. Barcelona: Editorial Ariel Educación, 2011.

. La educación informal. Barcelona: PPU, 1987.

URRY, John. O olhar do turista: lazer e viagem nas sociedades contemporâneas. São Paulo: Nobel, 1996.

WORCMAN, Katrin. As histórias e seus usos. SANTHIAGO, Ricardo; MAGALHÃES, Valéria Barbosa (Orgs.). Depois da utopia: a história oral em seu tempo. São Paulo: Letra e Voz: Fapesp, 2013. 